\title{
Ácido indolbutírico em diferentes diâmetros na estaquia de Luehea divaricata
}

\author{
Indolbutyric acid in different diameters on the vegetative propagation of Luehea divaricata
}

\section{RESUMO}

Luehea divaricata Mart. é uma árvore de porte médio com madeira resistente e de grande flexibilidade, características que a qualificam como matéria-prima na fabricação de móveis vergados. Devido à relevância desta espécie em indústrias de base florestal, o objetivo deste trabalho foi avaliar o efeito do ácido indolbutírico e do diâmetro da estaca como subsídio à produção de matrizes adequadas ao uso comercial. Foram utilizadas estacas com $20 \mathrm{~cm}$ de comprimento, coletadas de matrizes com aproximadamente dez anos de idade. Os tratamentos consistiram na combinação entre estacas com três classes de diâmetro: finas $(0,4-0,8 \mathrm{~cm})$, médias $(0,9-1,4 \mathrm{~cm})$, grossas $(1,5-2,6 \mathrm{~cm})$ e dois níveis de solução de ácido indolbutírico $\left(0 ; 5000 \mathrm{mg} \mathrm{L}^{-1}\right)$. O delineamento experimental foi inteiramente casualizado, consistindo de 12 unidades experimentais por repetição e cinco repetições por tratamento. Aos 90 dias após a implantação do experimento, foram avaliadas as variáveis: sobrevivência, enraizamento, número e comprimento radicial. Estacas médias e grossas imersas em $5000 \mathrm{mg} \mathrm{L}^{-1}$ de solução hidroalcoólica de IBA são indicadas na estaquia de Luehea divaricata.

Palavras-chave: auxina, enraizamento, madeira, propagação.

\section{ABSTRACT}

Luehea divaricata Mart. is a medium-sized-tree of a resistent wood and great flexibility, characteristics which qualify it as raw material in the manufacture of furniture. Due to the relevance of this species to the forest based industry the project was conducted in order to investigate the indolbutyric acid and the diameter of the stem cuttings as a subsidy for the production of matrices adequate for comercial use. Stem cuttings of $20 \mathrm{~cm}$ of length taken from matrices of approximately ten years of age were used. The treatments consisted of the combination between stem cuttings of three classes of diameter: fine $(0.4-0.8 \mathrm{~cm})$, medium $(0.9-1.4 \mathrm{~cm})$ and thick $(1.5-2.6 \mathrm{~cm})$ and two levels of solution IBA $\left(0,5000 \mathrm{mg} \mathrm{L}^{-1}\right)$. A completely randomized experimental design was used and consisted of bifactorial combinations with 12 units per repetition and five repetitions per treatment. 90 days after the implantation of the experiment the following variables were evaluated: survival, rooting, number and length of the roots. Thick and medium stem cuttings immersed in $5000 \mathrm{mg} \mathrm{L}^{-1}$ of hidroalcolic solution of IBA are indicated in the vegetative propagation of Luehea divaricata.

Key words: auxin, rooting, wood, propagation.

\section{INTRODUÇÃO}

Estimativas sobre a contribuição das florestas nativas em indústrias de base florestal indicam que de um total de 300 milhões de metros cúbicos de madeira consumidos anualmente no Brasil, 190 milhões são provenientes de florestas nativas (LADEIRA, 2002; GONÇALVES, 2005). Entretanto, alguns segmentos de base florestal, como é o caso da indústria moveleira, já sentem o déficit de oferta interna de madeira (JUVENAL \& MATTOS, 2002). Nesse cenário, é necessária a adoção de metodologias que contribuam para aumentar a produção de madeira destinada a este setor.

Luehea divaricata, popularmente conhecida como açoita-cavalo, é uma árvore da família Tiliaceae com ocorrência do sul da Bahia ao Rio Grande do Sul (LORENZI, 1998). Ela apresenta madeira de qualidade, com média retratibilidade e baixa resistência mecânica e é indicada para confecção de móveis vergados e peças torneadas (RIZZINI, 1971). Ela propaga-se facilmente por via sexuada, entretanto, obtém-se, na maioria das vezes, indivíduos de fuste tortuoso, inadequados ao uso comercial.

IDepartamento de Pós-graduação de Engenharia Florestal, Universidade Federal de Santa Maria (UFSM), Santa Maria, RS, Brasil.

*Endereço para correspondência: Rua Erly de Almeida Lima, nº 195, apto 302, 97105120. Email: jardelcb@yahoo.com.br. 
No Estado do Rio Grande do Sul, a exploração de Luehea divaricata tem apresentado caráter predatório, reduzindo drasticamente os exemplares com características adequadas ao uso (FARIAS, 2006). Conseqüentemente, grande parte das árvores encontradas, atualmente, não apresenta condições de serem aproveitadas pela indústria madeireira, tendo em vista a elevada tortuosidade de fuste. Essas limitações podem ser resolvidas por meio de técnicas de propagação vegetativa, entre as quais, a estaquia é freqüentemente utilizada.

Para espécies que podem ser propagadas vegetativamente, a estaquia apresenta inúmeras vantagens (WASSNER \& RAVETTA, 2000). Além de permitir com que as características de interesse sejam mantidas, ela pode aumentar, consideravelmente, a qualidade dos plantios florestais (MCKEAND et al., 2006). O sucesso no plantio de mudas clonais está, invariavelmente, ligado ao desenvolvimento radicial das estacas, portanto, é necessário observar não somente o percentual de enraizamento, mas também o número e o comprimento radicial (ROCHA CORREA \& FETT-NETO, 2004).

A formação de raízes adventícias pode ser influenciada por fatores internos e externos às estacas (DAVIES et al., 1987). É consenso que as auxinas desempenham importante função na indução e no crescimento de raízes adventícias, de modo que baixos teores de auxina podem limitar a formação radicial (NAG et al., 2001). Esse obstáculo pode ser resolvido empregando-se reguladores vegetais, especificamente o ácido indolbutírico (IBA), que, além de estimular o enraizamento das estacas, promove maior uniformidade ao sistema radicular (ONO et al., 1994).

Em espécies lenhosas, a formação de raízes adventícias está relacionada ao diâmetro da estaca (DICKMANN et al., 1980). A relação entre ambos tem origem no grau de lignificação e, conseqüentemente, no teor de compostos fenólicos (CFs) e peroxidases (PXs). Estudos demonstram que o teor de ligninina está negativamente relacionado aos CFs, entretanto, diretamente relacionado às PXs (LIU et al., 1996; FAIVRE-RAMPANT et al., 2002). Atividades como oxidação e catabolismo da auxina endógena dependem do teor de CFs e PXs, indicando que estacas com diferentes diâmetros e lignificação podem diferir na formação radicial (NORMANLY et al., 1995).

Considerando o potencial desta espécie como fonte de matéria-prima para indústrias moveleiras e a perspectiva de exploração econômica em áreas de florestas nativas, objetivou-se avaliar a influência do ácido indolbutírico no enraizamento de estacas de Luehea divaricata com diferentes classes de diâmetro.

\section{MATERIAL E MÉTODOS}

O experimento foi realizado no Viveiro Florestal da Universidade Federal de Santa Maria (UFSM), no período de março a junho de 2005. Forma coletados ramos de cinco matrizes adultas (dez anos), localizadas em mata sucessional secundária em Santa Maria, RS, situada entre os paralelos $29^{\circ} 43^{\prime}$ 57' ' e $29^{\circ}$ $55^{\prime} 30^{\prime \prime}$ de latitude sul e entre os meridianos $53^{\circ} 42^{\prime} 13^{\prime \prime}$ e $53^{\circ} 48^{\prime}$ '” de longitude oeste. Foram confeccionadas 360 estacas lenhosas, da porção mediana dos ramos, com $20 \mathrm{~cm}$ de comprimento, sem folhas, sendo cortadas horizontalmente acima $(1 \mathrm{~cm})$ do nó superior e em bisel abaixo $(1 \mathrm{~cm})$ do nó inferior. Os tratamentos consistiram na combinação entre estacas com três classes de diâmetro, finas $(0,4-0,8 \mathrm{~cm})$, médias $(0,9-1,4 \mathrm{~cm})$ e grossas (1,5-2,6cm) e dois níveis de solução IBA (0 e $5000 \mathrm{mg} \mathrm{L}^{-1}$ ). O delineamento experimental foi inteiramente casualizado consistindo de 12 unidades experimentais por repetição e cinco repetições por tratamento.

As estacas submetidas à aplicação do regulador vegetal tiveram suas bases imersas (dez segundos) em solução contendo $5000 \mathrm{mg} \mathrm{L}^{-1}$ IBA previamente diluído em $50 \%$ de álcool etílico $\left(98^{\circ} \mathrm{GL}\right) \mathrm{e}$ $50 \%$ de água destilada. Para o tratamento controle, a imersão foi realizada em água destilada e álcool etílico na proporção de $1: 1 \mathrm{v} / \mathrm{v}$. O estaqueamento foi realizado em sacos de polietileno $(15 \times 10 \mathrm{~cm})$, contendo areia como substrato. A condução do experimento foi realizada sob telado de sombrite $25 \%$, em condições naturais de temperatura, com quatro aspersões diárias, tendo cada uma duração de dez minutos. Aos 90 dias após a implantação do experimento, foram avaliadas as seguintes variáveis: sobrevivência, enraizamento, número e comprimento radicial.

Os dados em porcentagem foram transformados pela equação arco seno v(x /100) e os dados de contagem pela equação $\mathrm{v}(\mathrm{x}+1)$, seguindo distribuição normal. Posteriormente, os dados foram submetidos à análise de variância pelo procedimento GLM (General Linear Model). As diferenças entre as médias foram comparadas pelo teste de Tukey a 5\% de probabilidade de erro. As análises estatísticas foram realizadas pelo software MINITAB (MACKENZIE \& GOLDMAN, 1999).

\section{RESULTADOS E DISCUSSÃO}

Os valores médios das variáveis sobrevivência, enraizamento, número e comprimento radicial são apresentados na tabela 1 . Não houve interação entre diâmetro e ácido indolbutírico na 
Tabela 1 - Valores médios para sobrevivência, enraizamento, número de raízes e comprimento radicial (cm) em estacas finas, médias e grossas de Luehea divaricata Mart. com 0; 5000 $\mathrm{mg} \mathrm{L}^{-1}$ ácido indolbutírico. Santa Maria, RS, 2005.

\begin{tabular}{|c|c|c|c|c|}
\hline \multirow[t]{2}{*}{ Tratamento } & \multirow{2}{*}{-------Estaca------- } & \multicolumn{3}{|c|}{-------------------------------------------Raízes----------------------------------------- } \\
\hline & & Enraizamento (\%) & Número & Comprimento $(\mathrm{cm})$ \\
\hline \multicolumn{5}{|l|}{ Diâmetro } \\
\hline Fino & $26,2^{\mathrm{a}}$ & $15,4^{\mathrm{a}}$ & $1,23^{\mathrm{a}}$ & $2,63^{\mathrm{a}}$ \\
\hline Médio & $36,4^{\mathrm{b}}$ & $22,6^{\mathrm{b}}$ & $1,76^{\mathrm{a}}$ & $4,36^{\mathrm{b}}$ \\
\hline Grosso & $43,4^{\mathrm{b}}$ & $25,8^{\mathrm{b}}$ & $2,30^{\mathrm{a}}$ & $6,79^{b}$ \\
\hline \multicolumn{5}{|l|}{ IBA $\left(\mathrm{mg} \mathrm{L}^{-1}\right)$} \\
\hline 0 & $39,4^{\mathrm{a}}$ & $17,6^{\mathrm{a}}$ & $1,45^{\mathrm{a}}$ & $3,57^{\mathrm{a}}$ \\
\hline 5000 & $31,2^{\mathrm{a}}$ & $24,9^{\mathrm{b}}$ & $2,08^{\mathrm{b}}$ & $5,67^{\mathrm{b}}$ \\
\hline $\mathrm{dpr}^{1}$ & 13,9 & 13,5 & 0,94 & 2,23 \\
\hline \multicolumn{5}{|l|}{$\mathrm{P}$} \\
\hline Diâmetro (D) & 0,002 & 0,038 & 0,060 & 0,016 \\
\hline IBA & 0,477 & 0,004 & 0,007 & 0,003 \\
\hline $\mathrm{D} * \mathrm{IBA}$ & 0,230 & 0,019 & 0,083 & 0,071 \\
\hline
\end{tabular}

${ }^{1}$ Médias com letras distintas, na mesma coluna, diferem pelo teste de Tukey em nível de 5\% de probabilidade de erro.

sobrevivência das estacas. O diâmetro da estaca influenciou a sobrevivência das estacas. Estacas grossas apresentaram os maiores valores de sobrevivência, aproximadamente $65 \%$ superior às estacas finas. A aplicação de IBA não influenciou a sobrevivência das estacas.

A influência do diâmetro na sobrevivência pode ser explicada pelas diferenças no teor de carboidratos e lignificação das estacas. A disponibilidade de carboidratos é considerada um fator limitante a sobrevivência, pois representa a principal fonte de energia assimilável para o enraizamento e manutenção das atividades metabólicas das estacas (VEIERSKOV, 1988). Dessa forma, estacas grossas seriam favorecidas pelas maiores reservas de carboidratos disponíveis. Além disso, é provável que o maior espessamento esclerenquimático das estacas grossas tenha reduzido a perda de água dos tecidos, característica observada por outros autores (FACHINELLO et al., 1995). A perda de água reduz a pressão de turgor celular além de comprometer diversos processos fisiológicos na planta (PÁEZ et al., 1995). Portanto, acredita-se que as atividades dependentes do turgor celular como a expansão foliar e o enraizamento tenham sido limitadas pelo déficit hídrico em estacas finas (NÓBREGA et al., 2001).

O enraizamento foi influenciado pela interação entre diâmetro da estaca e ácido indolbutírico (Tabela 2). Estacas grossas tratadas em solução de $5000 \mathrm{mg} \mathrm{L}^{-1}$ apresentaram maior percentual de enraizamento. Houve efeito do diâmetro sobre o número de estacas enraizadas, sendo observado, em estacas grossas, aumento de até $25 \%$ em relação às estacas finas. A aplicação de IBA aumentou em $40 \%$ o enraizamento das estacas grossas, nesse caso, em comparação com as estacas finas.

A multiplicação das células rizogênicas depende, entre outros fatores, da biossíntese de proteínas e ácidos nucléicos (FACHINELLO et al., 1995). Entretanto, esse processo só é possível quando existe disponibilidade de energia e carbono estrutural para formação de novas células (RAPAKA et al., 2007). A interação entre auxina e diâmetro da estaca é característica já conhecida, tendo sido verificada por NEMETH (1986) e LEON \& SHEEN (2003). Neste experimento, estacas grossas, freqüentemente relacionadas a maiores reservas de carboidratos, apresentaram maior enraizamento em solução de 5000 $\mathrm{mg} \mathrm{L}^{-1}$ IBA, indicando sinergismo entre os fatores na determinação desta variável.

Considerando-se exclusivamente o fator diâmetro, podemos admitir que existem variações no teor de peroxidases, IAA oxidases e compostos fenólicos nas estacas. Tecidos mais lignificados, como é o caso das estacas grossas, apresentam maior teor de peroxidases e IAA oxidases, ambos envolvidos na degradação do ácido indolacético em conjugados inativos. Esperava-se, portanto, que houvesse redução do enraizamento conforme aumento no diâmetro das estacas, fato não observado neste estudo. Dessa forma, é provável que estacas grossas tenham sido beneficiadas pela maior disponibilidade de carboidrato armazenado. Os carboidratos são moléculas orgânicas que fornecem aporte estrutural e energético ao

Ciência Rural, v.38, n.6, set, 2008. 
Tabela 2 - Interação entre as concentrações de ácido indolbutírico (IBA) e tipo (diâmetro) da estaca sobre o enraizamento de Luehea divaricata Mart. Santa Maria, RS, 2005.

\begin{tabular}{lc}
\hline Diâmetro x IBA $\left(\mathrm{mg} \mathrm{L}^{-1}\right)$ & Enraizamento (\%) \\
\hline Fino x 0 & $13,28^{\mathrm{a}}$ \\
Fino x 5000 & $17,61^{\mathrm{ab}}$ \\
Médio x 0 & $18,77^{\mathrm{ab}}$ \\
Médio x 5000 & $26,46^{\mathrm{ab}}$ \\
Grosso x 0 & $20,98^{\mathrm{ab}}$ \\
Grosso x 5000 & $30,68^{\mathrm{b}}$ \\
dpr & 13,5 \\
P & 0,019 \\
\hline
\end{tabular}

${ }^{1}$ Médias com letras distintas, na mesma coluna, diferem pelo teste de Tukey em nível de 5\% de probabilidade de erro.

enraizamento, estando ainda envolvidos na expressão gênica e no controle do ciclo celular (LYTOVCHENKO et al., 2007). Outros autores também observaram a influência do diâmetro da estaca sobre a formação de raízes adventícias, sendo observados maiores valores em estacas grossas (BARTOLINI et al., 2000; DIAS et al., 1999).

A formação de raízes adventícias pode ocorrer espontaneamente, entretanto, na maioria das vezes, depende da aplicação exógena de fitorreguladores (HAISSIG et al., 1992). Neste experimento, estacas não tratadas com IBA, independente do diâmetro, apresentaram enraizamento significativamente menor àquelas com aplicação de ácido indolbutírico. Comportamento similar foi observado em estacas de Ebenus cretica, consideradas de difícil enraizamento (SYROS et al., 2004). O efeito do IBA sobre a formação de raízes adventícias está relacionado à expressão de genes de resposta ao fitorregulador (GRFs). O aumento da elongação, multiplicação e diferenciação estão entre as principais respostas resultantes da expressão dos GRFs, que, neste estudo, foram confirmadas pelo número de estacas enraizadas e comprimento radicial em Luehea divaricata (ABEL \& THEOLOGIS, 1996). De qualquer modo, as respostas obtidas indicam necessidade de aplicação de fitorregulador, uma vez que houve aumento de $40 \%$ no enraizamento das estacas tratadas com ácido indolbutírico.

Não houve interação entre diâmetro e IBA para o número de raízes. O diâmetro da estaca não apresentou influência sobre o número de raízes. A aplicação de IBA aumentou em até $43 \%$ o número de raízes em estacas de Luehea divaricata.

O número de raízes está relacionado à ação de auxinas sobre células alvo, que devido a estímulos hormonais, retomam a capacidade de diferenciação celular (CASIMIRO et al., 2003). Estudos genéticos e fisiológicos demonstram que o enraizamento ocorre em três fases características: indução, iniciação e expressão celular (SYROS et al., 2004). É na fase de indução radicial que estacas tratadas com fitorreguladores parecem diferir em relação ao número de raízes (MITSUHASHIKATO et al., 1978). Esse comportamento pode estar relacionado à ativação de fatores de transcrição (FTs) pela aplicação de auxina (DHARMASIRI \& ESTELLE, 2004). Os FTs são proteínas que atuam como mediadores na ativação de genes específicos, também chamados de genes de resposta as auxinas. É provável que o aumento do número de raízes em estacas tratadas com IBA esteja relacionado à expressão de genes modulados por fatores de transcrição.

Não houve interação entre diâmetro e IBA para o comprimento das raízes. Estacas grossas apresentaram maior comprimento de raízes $(6,7 \mathrm{~cm})$, seguido pelas médias $(4,3 \mathrm{~cm})$ e finas $(2,6 \mathrm{~cm})$, respectivamente. A aplicação de IBA influenciou o comprimento das raízes, obtendo-se aumento de aproximadamente $58 \%$ em relação às estacas do tratamento controle.

O comprimento radicial pode aumentar em função do diâmetro da estaca, fato explicado pela variação no teor de carboidratos. Os carboidratos constituem a principal fonte de energia disponível ao desenvolvimento radicial, podendo representar até 75\% da massa seca em espécies lenhosas (KRAMER \& KOZLOWSKI, 1979; LATT et al., 2001). Dessa forma, acredita-se que o maior comprimento radicial esteja relacionado com as maiores reservas de carboidratos em estacas grossas.

O aumento do comprimento radicial em estacas tratadas com IBA pode estar relacionado a alterações na extensibilidade da parede celular pela ativação das expansinas. As expansinas são proteínas específicas que, em $\mathrm{pH}$ ácido, aumentam a extensibilidade da parede por meio do afrouxamento das ligações não-covalentes entre os polissacarídeos da parede (LEE., et al., 2001). As condições ideais para ativação das expansinas dependem da ação das auxinas sobre proteínas H+-ATPases da membrana plasmática, as quais aumentam a atividade em presença de auxinas (TAIZ \& ZEIGER, 2004). Conseqüentemente, o afrouxamento das ligações não-covalentes da parede implica maior alongamento celular, que, provavelmente, refletiu no comprimento radicial em estacas de Luehea divaricata tratadas com ácido indolbutírico. Além disso, estudos indicam que as auxinas estão envolvidas no controle das quinases dependentes da ciclina (CDK). As quinases são enzimas que controlam a progressão entre os diferentes estágios do ciclo celular 
bem como a entrada das células em processo mitótico (TAIZ \& ZEIGER, 2004). A ativação dessas enzimas depende de subunidades protéicas chamadas de ciclinas, que, em conjunto com a CDK, respondem pelos processos de divisão celular (BURSSENS et al., 1998). Estudos indicam que as auxinas podem aumentar a expressão de genes que codificam as proteínas dependentes da quinases, bem como de suas subunidades ativadoras, as ciclinas (SUCHOMELOVA et al., 2004). Portanto, acredita-se que o comprimento radicial em estacas de Luehea divaricata tratadas com IBA apresente relação com o controle do ciclo celular induzido por auxinas.

\section{CONCLUSÕES}

Os resultados obtidos permitem concluir que estacas médias e grossas imersas em 5000mg L $\mathrm{L}^{-1}$ de solução hidroalcoólica de ácido indolbutírico são indicadas na estaquia de Luehea divaricata.

\section{REFERÊNCIAS}

ABEL, S.; THEOLOGIS, A. Early genes and auxin action. Plant Physiology, v.111, p.9-17, 1996.

BARTOLINI, G. et al. Parameters that influence rooting and survival of peach cuttings. Journal of the American Pomological Society, v.54, p.183-188, 2000.

BURSSENS, S. et al. The cell cycle in Arabidopsis. Plant Physiology and Biochemistry, v.36, p.9-19, 1998.

CASIMIRO, I. et al. Dissecting Arabidopsis lateral root development. Trends in Plant Science, v.8, p.165-171, 2003.

DAVIES, T. D. et al. Adventitious root formation in cuttings. Portland: Dioscorides, 1987. 316p.

DHARMASIRI, N.; ESTELLE, M. Auxin signaling and regulated protein degradation. Trends in Plant Science, v.9, p.302308, 2004.

DIAS, R.M.S.L. et al. Enraizamento de estacas de diferentes diâmetros em Platanus acerifolia (Aiton) Willdenow. Ciência Florestal, v.9, p.127-136, 1999.

DICKMANN, D. et al. Cutting diameter influences early survival and growth of several Populus clones. Saint Paul, Minnesota: Forest Service, North Central Forest Experiment Station, 1980. 4p.

FACHINELLO, J.C. et al. Propagação de plantas frutíferas de clima temperado. Pelotas: UFPel, 1995. 178p.

FAIVRE-RAMPANT, O. et al. Cuttings of the non-rooting rac tobacco mutant overaccumulate phenolic compounds. Functional Plant Biology, v.29, p.63-71, 2002.

FARIAS, J.A.D. Contribuicao para a silvicultura de Luehea divaricata Martius et Zuccarini (Acoita-Cavalo). 2006. 69f. Dissertação (Mestrado em Engenharia Florestal) - Curso de Pós-graduação em Engenharia Florestal, Universidade Federal de Santa Maria.

GONÇALVES, B.S. O compromisso das empresas com o meio ambiente - Agenda ambiental das empresas e a sustentabilidade da economia florestal. São Paulo: Instituto Ethos, 2005. 48p.

HAISSIG, B.E. et al. Researching the controls of adventitious rooting. Physiologia Plantarum, v.84, p.310-317, 1992.

JUVENAL, T.L.; MATTOS, R.L.G. O setor florestal no Brasil e a importância do reflorestamento. BNDES setorial, v.1, p.3-30, 2002.

KRAMER, P.J.; KOZLOWSKI, T.T. Physiology of woody plants. New York: Academic, 1979. p.258-274.

LADEIRA, H. Quatro décadas de Engenharia Florestal no Brasil. Viçosa: Sociedade de Investigações Florestais, 2002. 207p.

LATT, C.R. et al. Reserve carbohydrate levels in the boles and structural roots of five multipurpose tree species in a seasonally dry tropical climate. Forest Ecology and Management, v.146, p.145-158, 2001.

LEE, Y. et al. Expansins: ever-expanding numbers and functions. Current Opinion in Plant Biology, v.4, p.527-532, 2001.

LEON, P.; SHEEN, J. Sugar and hormone connections. Trends in Plant Science, v.8, p.110-116, 2003.

LIU, Z.H. et al. Effect of naphthaleneacetic acid on endogenous indole-3-acetic acid, peroxidase and auxin oxidase in hypocotyl cuttings of soybean during rootformation. Botanical Bulletin of Academia Sinica, v.37, p.247-253, 1996.

LORENZI, H. Manual de identificação e cultivo de plantas arbóreas nativas do Brasil. Nova Odessa: Plantarum, 1998. 352p.

LYTOVCHENKO, A. et al. The complex network of noncellulosic carbohydrate metabolism. Current Opinion in Plant Biology Physiology and Metabolism, v.10, p.227235, 2007.

MCKEAND, S.E. et al. Performance of improved genotypes of loblolly pine across different soils, climates, and silvicultural inputs. Forest Ecology and Management, v.227, p.178184, 2006.

MACKENZIE, J.; GOLDMAN, R.N. The student edition of Minitab for windows manual: release 12 . Belmont: Addison-Wesley Longman, 1999. 592p.

MITSUHASHI-KATO, M. et al. The nature of the dual effect of auxin on root formation in Azukia cuttings. Plant Cell Physiology, v.19, p.1535-1542, 1978.

NAG, S. et al. Role of auxin and polyamines in adventitious root formation in relation to changes in compounds involved in rooting. Journal of Plant Growth Regulation, v.20, p.182-194, 2001.

Ciência Rural, v.38, n.6, set, 2008. 
NEMETH, G.I. Induction of rooting. In: BAJAJ, Y.P.S Biotechnology agriculture and forestry. Berlim: SpringerVerlag, 1986. p.49-64.

NÓBREGA, J.Q. et al. Análise de crescimento do feijoeiro submetido a quatro níveis de umidade do solo. Revista Brasileira de Engenharia Agrícola e Ambiental, v.5, p.437443, 2001.

NORMANLY, J. et al. Rethinking auxin biosynthesis and metabolism. Plant Physiology, v.107, p.323-329, 1995.

ONO, E. O. et al. Enraizamento de estacas de Platanus acerifolia, tratadas com auxinas. Pesquisa Agopecuária Brasileira, v.29, p.1373-1380, 1994.

PÁEZ, A. et al. Water stress and clipping management effects on guinea grass: Growth and biomass allocation. Agronomy Journal, v.87, p.698-706, 1995.

RAPAKA, V.K. et al. Diurnal carbohydrate dynamics affect postharvest ethylene responsiveness in portulaca (Portulaca grandiflora 'Yubi Deep Rose') unrooted cuttings. Postharvest Biology and Technology, v.44, p.293-299, 2007.

RIZZINI, C.T. Árvores e madeiras úteis do Brasil - Manual de dendrologia Brasileira. São Paulo: Edgard Blücher, 1971. $294 p$.
ROCHA CORREA, L.D.; FETT-NETO, A.G. Effects of temperature on adventitious root development in microcuttings of Eucalyptus saligna Smith and Eucalyptus globulus Labill. Journal of Thermal Biology, v.29, p.315-324, 2004.

SUCHOMELOVA, P. et al. Expression of the fission yeast cell cycle regulator cdc25 induces de novo shoot formation in tobacco: evidence of a cytokinin-like effect by this mitotic activator. Plant Physiology and Biochemistry, v.42, p.4955, 2004.

SYROS, T. et al. Activity and isoforms of peroxidases, lignin and anatomy, during adventitious rooting in cuttings of Ebenus cretica L. Journal of Plant Physiology, v.161, p.69-77, 2004.

TAIZ, L.; ZEIGER, E. Fisiologia vegetal. Porto Alegre: Artmed, 2004. 719p.

VEIERSKOV, B. Relations between carbohydrates and adventitious root formation. In: DAVIES, T.D. et al. Adventitious root formation in cuttings. Portland: Dioscorides, 1988. p.70-78.

WASSNER, D.; RAVETTA, D. Vegetative propagation of Grindelia chiloensis (Asteraceae). Industrial Crops and Products, v.11, p.7-10, 2000. 